\title{
Outcome of Lumbar Trans-Pedicular Fixation in Management of Recurrent Lumber Dise Herniation
}

\author{
AHMED M. NABEEL, M.D.*; MAHMOUD M. WAHDAN, M.D.*; ATEF A. SALEM, M.D.**; \\ MOHAMED A. MANSOUR, M.D.** and ALI S. ALI, M.Sc.* \\ The Departments of Neurosurgery* and General Surgery**, Faculty of Medicine, Benha University
}

\begin{abstract}
Background: Recurrent lumbar disc herniation is one of the common problems facing most of neurosurgeons and spine surgeons. Treatment options include conservative management (pharmacological and physical therapy) and finally surgical intervention. Surgical options include repeat discectomy and adhesolysis with or without instrumented spinal fusion. Fusion is usually suggested for patients with deformity, instability, or associated axial low back pain.
\end{abstract}

Aim of Study: This study aims to evaluate the role of trans-pedicular fixation in the management of recurrent lumbar disc herniation.

Patients and Methods: The study was carried out on 20 patients with recurrent lumber disc herniation underwent surgery for discectomy with trans-pedicular fixation with postero-lateral inter-transverse fusion at neurosurgery department at Benha university hospital, in the duration between $12 / 2016$ to $12 / 2018$ with minimum follow-up 6 months. All the patients were clinically examined carefully, Preoperatively and post-operatively, low back pain and radiculopathy were assessed by visual analogue score (VAS). Patients were radiologicaly investigated by MRI and dynamic X-rays.

Results: All the patients were improved clinically immediately after surgery. The Median VAS for back pain and radiculopathy significantly decreased from 8 pre-operatively to 2 post-operatively. Post-operative radiological assessment was done for all 20 patients by CT LSS to asses accuracy of instrumentation and fusion.

Conclusion: Using Trans-pedicular fixation and fusion for treatment of recurrent LDP provide adequate Clinical improvement for LBP and sciatica giving chance for better nerve root decompression and avoid mico-instability.

Key Words: Recurrent - Lumbar disc prolapse - Fixation.

\section{Introduction}

MOST literatures usually define recurrent lumbar disc herniation (RLDH) as ipsilateral Or contralateral disc herniated at the same level of previous

Correspondence to: Dr. Ahmed M. Nabeel, E-Mail: ahmed m nabeel@yahoo.com surgery, that causes symptoms of radiculopathy after a symptom-free interval of at least 6 months postoperatively [1-3]

Recurrent lumbar disc herniation is a major cause of complications after primary surgery for lumbar disc prolapse, often causing more severe sciatica than the primary herniation [4] . Many authors found that this recurrence appears clinically in about $5-15 \%$ of patients underwent primary lumbar discectomy $[2,5,6]$.

There have been many factors that influence the recurrence of lumbar disc herniation. While bio-mechanical and anatomical changes during surgery inherently increase risk, there may be other modifiable factors affect this recurrence such as smoking, obesity, extent of annular incision $[2,6,7]$ and diabetes mellitus, these factors could be managed preoperatively to decrease the risk of such complication [3].

Low back pain is usually the initial complaint in recurrent lumbar disc herniation, which is usually dull, diffuse, aching pain of gradual onset, worse on exertion and better on rest, it may be associated with muscular spasm and aggravated by movement. Back pain may persist for several days or weeks, and then it is usually followed by radicular pain [1]. Radiculopathy in patients with recurrent lumbar disc herniation is thought to be secondary to nerve root tethering $[1,8]$. It is often possible that a smaller amount of recurrent disc material to cause symptoms than in "a virgin back", as the nerve root is

\footnotetext{
List of Abbreviations:

RLDH : Recurrent lumbar disc herniation.

VAS : Visual analogue score.

CT LSS : Computerized tomography on lumbo-sacral spine.

MRI : Magnetic resonance image.

LBP : Low back pain.
} 
often fixed by adhesions and has little ability to deviate away from the disc fragment [9].

The surgical treatment for recurrent herniated lumbar discs usually has advantagesover non operative one. Two randomized clinical trials havedemonstrated that patients who receiving operative intervention have fasterresolution of pain and regain their usual activity more rapidly than those managed non-operatively $[\mathbf{1 0 , 1 1}]$. While many surgeons prefer repeat discectomy alone, others support using many methods of fusion. Minimally invasive techniques such as spinal endoscopy for revision surgery following recurrent disc herniation have also been well described, but it is highly demanding and usually needs specific training $[12,13,14]$. Current recommendations suggest consideration for fusion in patients with significant deformity, instability, or associated axial low back pain $[15,16,17]$.

Discectomy with fusion has a lot of theoretical advantages. Fusion reduces or eliminates segmental motion, immobilizes the spine, reducesmechanical stressesacross the disc space and has a high rate of fusion and fewincidence of construct failures [18].

\section{Aim of work:}

This study aims to evaluate the role of transpedicular fixation and postero-lateral intertransverse fusion in the management of recurrent lumber disc herniation.

\section{Patients and Methods}

The study was carried out on 20 patients collected from Benha University Hospitals, Neurosurgery Department with recurrent lumbar disc herniationfor the first time and underwent revision discectomy with trans-pedicular fixation and postero-lateral inter-transverse in the duration between $12 / 2016$ to $12 / 2018$ with minimum follow-up 6 months.

\section{Inclusion criteria:}

1-At least 6 months of pain free interval after the initial discectomy.

2- The presence of recurrent radicular pain unresponsive to conservative management for at least 6 weeks pre-operatively.

3- Positive radiological findings of recurrent LDP at the same level.

\section{Exclusion criteria:}

1- Multi-segmental spinal canal stenosis.

2- Adjacent level disc herniation.
3- Post operative Spondylolisthesis.

4- Other spinal pathology, traumatic vertebral fracture, scoliosis, infection, osteoporosis, serious systemic disease.

5- Recurrence for the second time.

\section{Preoperative assessment:}

All the patients were subjected to detailed history taking, complete clinical and neurological examination. A mostlyall of our patients were presented by low back pain and sciatica, only two of them had pre-operative deficit (dorsiflexion weakness grade 3/5). VAS was assessed for all patients preoperatively for both back pain and radiculopathy. Mean conservative treatment duration was ${ }^{3 \pm 1}$ months with minimum duration of 2 months.

All patients had preoperative L.S.S X-ray A-P view was done to assess the extent of bony removal. Also lateral dynamic views was done to assess for possible dynamic instability and patients suspected to have dynamic instability were excluded from the study. All patients had a preoperative L.S.S MRI with contrast that was done within 6 months before operation.

\section{Operative details:}

All the patients were subjected to routine midline back skin incision over the previous scar, the epidural scar was not routinely resected, but lateral adhesolysis around the nerve roots were fundamental. Sometimes total facetectomy were needed to insure nerve root untethering without injury.

After acceptable adhesolysis and nerve roots decompression. All cases were subjected to transpedicular fixation either they had facetectomy or not. Bone achieved from decompression were used for inter-transverse fusion after decortication of the transverse processes, and if it was insufficient bone graft from the iliac crest were used.

\section{Follow-up:}

Early clinical assessment for back pain and sciatica post operatively and any perioperative complications were recorded.CT lumbosacral spine was done for all patients the day after surgery to asses accuracy of instrumentation except the patient with foot drop CT was done at the same day and re-operated again for screw revision.

Patients were followed periodicallyafter discharge for assessment of back pain and sciaticalate clinical outcome were assessed at the last followup using VAS and for symptoms and signs of recurrence or complications. 


\section{Results}

This study was conducted on 20 patients with recurrent lumber disc herniation underwent surgery for discectomy and nerve root decompression with trans-pedicular fixation and postero-lateral intertransverse fusion at neurosurgery department at Benha university hospital.

General characteristics of the whole study population:

The mean age of the study population was 48 years - \pm 5 , it ranged (39-58 years old). 14 patients were males $(70 \%)$ and 6 were females $(30 \%)$. The most frequent occupation was heavy manual workers (7 patients). 12 patients (60\%) of the study population were smokers. 3 patients were diabetic, onewas hypertensive and 16 showed no comorbidities.

Regarding the preoperative MRI the most affected level was L4-L5 disc (60\%).

Mean surgery time was $3 \pm 1$ hours (2.5-5). And none of the patients needed blood transfusion.

Usually Patients without post-operative CSF leak were discharged the third day after surgery. Patients with dual tear and CSF leak post operative were admitted for 7 days until adequate wound healing and removal of the subfascial drain, Mean hospital stay was $4- \pm 2$ days $(\max 7)$. Mean time to return to work was $8 \pm 3$ weeks with maximum time 12 weeks.

\section{Clinical outcome:}

All patients were clinically improved shortly after surgery regarding LBP and sciatica. Followup duration were (6-28) months, mean 17.6 months. At the last follow-up. VAS for back pain it is significantly decreased from (6-9) to (1-3) postoperatively. ( $p$-value $<0.001)$. Regarding radiculopathy, VAS decreased from (7-9) pre-operatively to (1-3) post-operatively ( $p$-value $<0.001$ ). Wilcoxon signed ranks test was used (Fig. 1). Motor power in the two cases that had pre-operative motor weakness, remained the same post-operatively.

\section{Complications:}

The most frequent peri-operative complication was dural tear; 5 patients had intra-operative dural tear $(25.0 \%)$, only 3 of them had post operative CSF leak. Other complications were nerve root injury in one patient and superficial infection in another. Late complications as Hardware failure, recurrent disc herniation and instability were not recorded in any of the patients during the whole follow-up period.

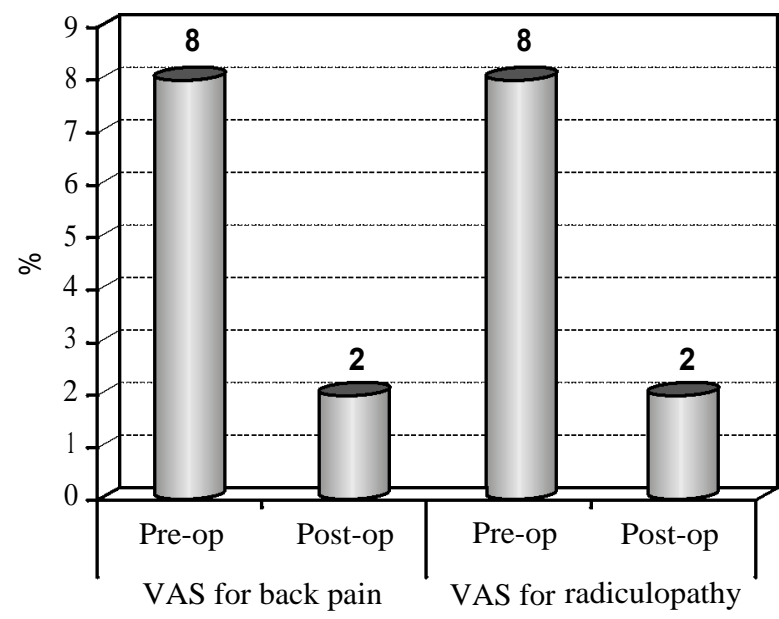

Fig. (1): Pre and post-operative Median VAS for back pain and radiculopathy.

\section{Discussion}

Recurrent herniation following initial lumbar disc surgery has been reportedin $5-15 \%$ of patients. The definition of recurrent disc herniation has varied among authors. In most studies, it was defined as disc herniation at the same level, regardless of ipsilateral or contralateral, with a pain-free interval more than 6 months $[2,5,6]$

Treatment options include conservative management (pharmacological therapy and physical therapy) and finally surgical intervention [3]. Surgical options include repeat discectomy with orwithout instrumented spinal fusion. When determining the optimal method for treatment, many factors should be considered; including patient symptoms, presence of axial low back pain, radiographic evidence of instability or deformity, surgeonpreference, and number of previous lumbar surgeries $[15,16,17]$

In our study, the age of patients ranges from 39 to 58 years old (mean: 48 years) which concedes with most of the studied on recurrent lumbar disc prolapsed [2,7,19]. Males were more than females as usual [7]. $60 \%$ of patients in our study had L45 recurrent LDP which is usually found as the most affected level in most of the studies on recurrent LDP $[\mathbf{1 , 2 0}$. Perhaps because of the increased mobility at L4-5 disc space relative to other spinal motion segments [1]. However in their series, Suri and pearson found that L5-S1 was the most Affected with incidence of 54\% [21]

In their study on Risk factors of recurrent lumbar disk herniation Shimia et al., divided cases according to their occupational characteristic into three groups; light (sitting and constant posture), 
housework (medium hard work), and heavy work (lifting or carrying heavy objects, forward leaning) [2]. It was familiar that The most frequent occupation in our series was heavy workers $(35.0 \%)$. Also $60 \%$ of our patients were smokers which support studies that considered smoking as a risk factor for recurrent lumbar disc herniation, otherwise our small group still cannot prove that $[7,10]$

Although discectomy and adhesolysis may be effective alone in improvement of radiclulopathy after surgery for recurrent lumbar disc disease $[4,15,22]$. Extensive bony excision and removal a large part of the facet may be needed in some cases to achieve nerve roots decompression and Iatrogenic instability in such cases usually happen [23]

Fusion after repeated discectomy have many advantages, in addition to removal of microinstability and mechanical stress across the disc space, we could claim that it give the surgeon the confidence for wider bony removal without giving attention for instability, giving the chance for more extensive nerve roots decompression which should improve the clinical outcome specially regarding sciatica, furthermore, with aggressive facetectomy surgeon usually can approach the residual disc fragment without excessive nerve root retraction, which theoretically should decrease the incidence of nerve root injury and even dural tear [24]. Although this make dissection and adhesolysis at more ease it did not decrease the incidence of dural tear in our series.

Most of the comparative studies showed better outcome specially regarding low back pain in fusion groups than non-fusion groups. $[\mathbf{1 9 , 2 4 , 2 5 , 2 6 ]}$ Although theoretically inter-body fusion should provide the most reliable fusion technique for the lumbar spine, others reported that both Trans foraminal inter-body fusion and postrolateral intertransverse fusion with revision discectomy had equal clinical outcome, rather than the thelesstotal cost in cases with postero-lateral inter-transverse fusion $[19,20]$. Significant clinical improvement in both low back pain and sciatica were noticed in our study, VAS markedly improved in the last clinical follow-up for all of the patients ( $p$-value $<0.001$ ).

No significant difference had been recorded among studies and ours regarding operative duration, blood loss and length of hospital stay. But Fu et al., in their study on long term results following disc excision for recurrent lumbar disc herniation with or without postero-lateral fusion (PLF) in 41 patients, they noticed that the discectomy only group had significantly less intraoperative blood loss, shorter durations of surgery and post-operative hospital stay [25].

Dural tear was the most common complication in our series, it occurred in 5 cases (25\%). Intraoperative Dural tear is usually common with surgery for recurrent LDP than virgin LDP cases which is actually due to adhesions and epidural scaring $[\mathbf{1 8 , 1 9 , 2 4 ]}$. In our technique, we tried hardly in all cases to dissect adhesions around the nerve roots for freeing it to allow better chance for improvement of radiculopathy, which my interpretate such high incidence, although we had 5 patients had intra-operative dural tear, only 3 of them had post-operative CSF leak and had to stay a whole week in the hospital post-operatively.

Post operative Nerve root injury or postoperative motor deficit were recorded in many series on surgery for recurrent LDP recorded $[4,15,19]$. Only one patient in our study have nerve root injury, he had immediate post op. foot drop with ankle dorsiflexion grade zero. It was mostly related to insertion of the screws, The patient was re-operated in the same day for screw revision after CT LSS was done and motor power returned after physiotherapy up to grade 3. Also only one of our patients had superficial wound infection that was treated medically and improved as well.

\section{Limitation of the study:}

The small number of patients in our series may limits statistics, but overall it is still could a descriptive study. We still recommend a comparative study between patients that had surgery for RLDP with and without fusion would be more beneficial.

\section{Conclusions:}

Adding Trans-pedicular fixation and postrolateral fusion for surgery of recurrent LDP provide adequate Clinical improvement for LBP and sciatica giving chance for better nerve root decompression, reduce the risk of nerve root injury and avoid micro-instability and recurrence.

Financial support \& sponsorship:

Nil.

Conflicts of interest:

There are no conflicts of interest.

\section{References}

1- HEARY R.F. and KARIMI R.J.: Evaluation, Indications, and Techniques of Revision Spine Surgery. In: Winn H.R., ed. Youmans neurological surgery, 6 th ed. Philadelphia: Elsevier Sauners, p. 2807, 2012. 
2- SHIMIA M., GHAZANI A.B., SADAT B.E., HABIBI B. and HABIBZADEH A.: Risk factors of recurrent lumbar disk herniation. Asian Journal of Neurosurgery, 8: 94 , 2013.

3- SWARTZ K.R. and TROST G.R.: Recurrent lumbar disc herniation. Neurosurg Focus, 15: E10, 2003.

4- DOWER A., CHATTERJI R., SWART A. and WINDER M.J.: Surgical management of recurrent lumbar disc herniation and the role of fusion. Journal of Clinical Neuroscience, 23: 44-50, 2016.

5- DRAZIN D., UGILIWENEZA B., AL-KHOUJA L., YANG D., JOHNSON P., KIM T. and BOAKYE M.: Treatment of Recurrent Disc Herniation: A Systematic Review. Cureus, 8 (5): e622, 2016.

6- SAKELLARIDIS N., BURTZINOS G., PETSANAS D., SPYRIDAKIS P.H., IATRELLI I., SAKELLARIDI L., MELIDONIS A. and GRIVAS T.H.: Can Post-Op Recurrent Lumbar Disc Disease be Prevented?. JSM Neurosurg. Spine, 3: 1, 2015

7- YAMAN M.E., KAZANC1 A., YAMAN N.D., BA F. and AYBERK G.: factors that influence recurrent lumbar disc herniation. Hong Kong Med. J., 23: 258-63, 2017.

8- ROSS J.S., ROBERTSON J.T., FREDERICKSON R.C., PETRIE J.L., OBUCHOWSKI N., MODIC M.T. and deTRIBOLET N.: Association between peridural scar and recurrent radicular pain after lumbar discectomy: Magnetic resonance evaluation. Anti-adhesion barrier gel (AdconL) European Study Group. Neurosurgery, 38 (4): 855-61, 1996.

9- GREEN BERG M.S.: Lumbar and Thoracic Intervertebral Disk Herniation / Radiculopathy. Handbook of neurosurgery / Mark S. Greenberg. Eighth edition. New York o Stuttgart • Delhi • Rio de Janeiro: Thieme, p. 1061, 2016.

10- HLUBEK R.J. and MUNDISS G.M.: Treatment for Recurrent Lumbar Disc Herniation. Curr. Rev. Musculoskelet Med. 10: 517-520, 2017.

11- PADUA R., PADUA S., ROMANINI E., PADUA L. and De SANTIS E.: Ten to 15 years outcome of surgery for lumbar disc herniation: Radiologic instability and clinincal finding. Eur. Spine J., 8:70-74, 1999.

12- HOOGLAND T., VAN DEN BREKEL-DIJKSTRA K., SCHUBERT M. and MIKLITZ B.: Endoscopic transforaminal discectomy for recurrent lumbar disc herniation: A prospective, cohort evaluation of 262 consecutive cases. Spine (Phila PA 1976), 33: 973-8, 2008.

13- RUETTEN S., KOMP M., MERK H. and GODOLIAS G.: Recurrent lumbar disc herniation after conventional discectomy: A prospective, randomized study comparing full-endoscopic interlaminar and transforaminal versus microsurgical revision. J. Spinal Disord Tech., 22: 1229, 2009 .
14- SHIN K.H., CHANG H.G., RHEE N.K. and LIM K.S. Revisional percutaneous full endoscopic disc surgery for recurrent herniation of previous open lumbar discectomy. Asian Spine J., 5: 1-9, 2011.

15- SHEPARD N. and CHO W.: Recurrent Lumbar Disc Herniation: A Review. Global Spine Journal, 1-8, 2017.

16- RESNIK D.K., CHOUDHRI T.F. and DAILEY A.T.: Guidelines for the performance of fusion procedures for degenerative disease of the lumbar spine. Part 8: Lumbar fusion for disc herniation and radiculopathy. J. Neurosurg. Spine, 2: 673-8, 2005.

17- ONYIA C.U. and MENON S.K.: The debate on most ideal technique for managing recurrent lumbar disc herniation: A short review. British Journal of Neurosurgery, 31 (6): 701-708, 2017.

18- ELSANAFIRY M.S., HANAFY A., AZABA A., AMMARA A.S. and ELSESY A.A.: The role of instrumented fusion in the management of recurrent lumbar disc herniation. Menoufia Med. J., 29: 642-645, 2016.

19- EL SHAZLY A.A., EL WARDANY M.A. and MORSI A.M.: Recurrent lumbardisc herniation: A prospective comparative study of threesurgical management procedures. Asian J. Neurosurg., 8: 139-146, 2013.

20- AGHAYEE H.N., AZHARI S. and HEIDARNEJAD F. The outcomes of surgical treatment of recurrent lumbar disk herniation with discectomy alone and discectomy with 9. Posterolateral interbody fusion. Novel Biomed, 2: 10-7, 2014

21- SURI P. and PEARSON A.M.: Pain Recurrence After Discectomy forSymptomatic Lumbar Disc Herniation. Spine, 42: 755-763, 2017.

22- PATEL N., POPLE I.K. and CUMMINS B.H.: Revisional lumbar microdiscectomy: An analysis of operative findings and clinical outcome. Br. J. Neurosurg., 9 (6): 733-737, 1995.

23- ROBERT M.G., MITCHEL B.H. and CHRISTOPHER M.B.: The role of fusion for recurrent disk herniations. Semin Spine Surg., 23: 242-248, 2011.

24- CHEN Z., ZHAO J., LIU A., YUAN J. and LI Z.: Surgical treatment of recurrent lumbar disc herniation by transforaminal lumbar interbody fusion. Int. Orthop., 33 (1): 197-201, 2009.

25- FU T.S., LAI P.L., NIU C.C., CHEN L.H. and CHEN W.J.: Long-term results of disc excision for recurrent lumbar disc herniation with or without posterolateral fusion. Spine (Phila PA 1976), 30: 2830-4, 2005.

26- CHOI J.Y., CHOI Y.W. and SUNG K.H.: Anterior lumbar interbody fusion in patients with a previous discectomy: Minimum 2-year follow-up. J. Spinal Disord Tech., 18 (4): 347-352, 2005 


\section{دورتثبيت الفقرات القطنية والعجرية

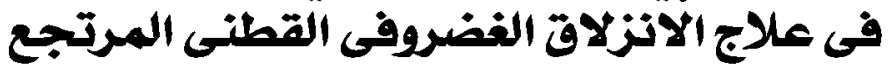

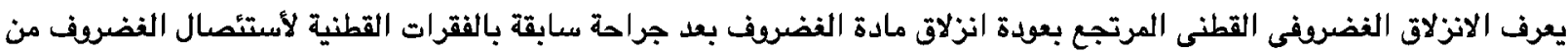

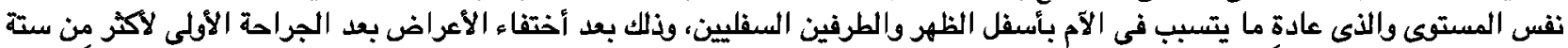

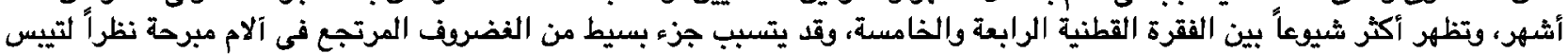

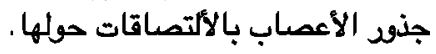

بالرغم من أنه يجب أن يبدأ علاج الأنزلاق الغضروفي المرتجع بالعلاج التحفظى إلا أن العلاج الجراحى عادة ما ئؤدى إلى نتائج جيدة.

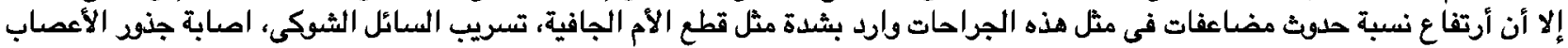

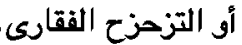

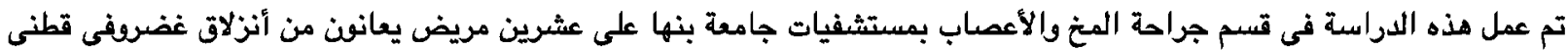

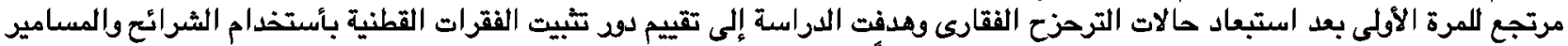

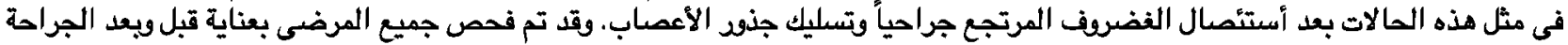

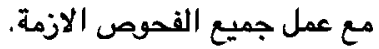

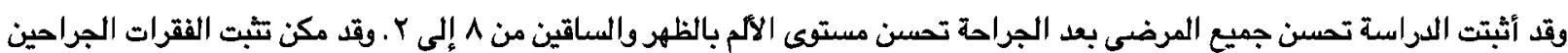

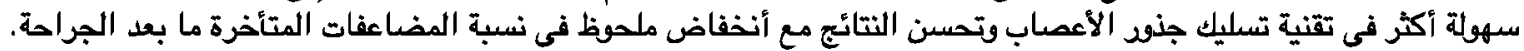

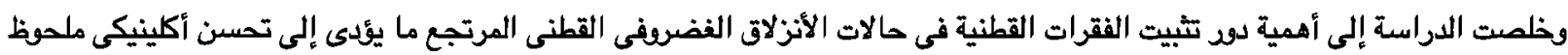

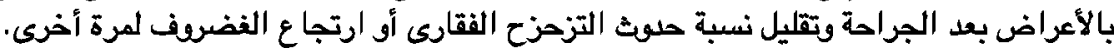

